\title{
Avaliação dos Benefícios de Previsões de Vazão na Operação de Reservatórios
}

\author{
Juan Martín Bravo, Walter Collischonn, Carlos Eduardo Morelli Tucci \\ Instituto de Pesquisas Hidráulicas - UFRGS \\ jumarbra@yahoo.com.ar, collischonn@iph.ufrgs.br,tucci@iph.ufrgs.br \\ Jorge Víctor Pilar \\ Facultad de Ingenieria, Universidad Nacional del Nordeste, Argentina. \\ jpilar@ing.unne.edu.ar \\ Benedito Cláudio da Silva \\ Universidade Federal de Itajubá - UNIFEI \\ silvabenedito@uol.com.br
}

Recebido: 30/08/07 - revisado: 19/11/07 - aceito: 29/02/08

\section{RESUMO}

O primeiro trabalho da seqüência apresentou uma metodologia de otimização da operação de um reservatório com base na previsão de vazão. Nesse trabalho foram avaliados os benefícios da previsão de vazão afluente de curto e longo prazo, na operação de um reservatório com dois usos conflitantes: geração de energia e controle de cheias. A simulação da operação do reservatório foi realizada com base em dois tipos de modelos para avaliar os benefícios da previsão. Um modelo de operação sem previsão e outro com previsão de vazão afluente. Regras de operação simples, na forma de curvas-guia lineares, foram utilizadas nos casos de operação com e sem previsão de vazões afluentes. As curvas-guia foram otimizadas através de uma técnica de parametrização, simulação e otimização utilizando um algoritmo evolucionário. A metodologia foi aplicada a um problema baseado nos dados do reservatório de Três Marias, no Rio São Francisco. Para avaliar o potencial benefício das previsões de vazão na operação do reservatório, foram realizados testes considerando as vazões afluentes observadas como "previsões perfeitas de vazão". Os resultados com previsões perfeitas de vazão mostram que pode haver um benefício relativo (incremento na geração de energia) de até $8 \%$, se forem utilizadas previsões de vazão de longo prazo com dois meses de antecedência, e se a operação for planejada com essa mesma antecedência no caso analisado. A operação baseada em previsões de prazos ou horizontes mais curtos apresenta beneficios inferiores, mas ainda assim significativos. Por exemplo, a previsão perfeita de vazão com freqüência semanal e horizonte de 12 dias pode trazer um benefício de aproximadamente 4,45\%. Esses benefícios foram obtidos com o mesmo desempenho no controle de cheias. Posteriormente foram realizados testes utilizando previsões de vazão de curto prazo obtidas a partir de previsões quantitativas de chuvas. Os benefícios obtidos com essas previsões são inferiores aos benefícios obtidos com as previsões perfeitas de curto prazo, como era esperado. Entretanto, representam valores superiores a $50 \%$ dos benefícios que seriam esperados com a previsão perfeita (vazões observadas). Os resultados obtidos são promissores e mostram que há vantagens evidentes na utilização de previsões quantitativas de chuva para se obter previsões de vazão na operação de reservatórios com usos múltiplos.

Palavras-chave: benefícios da previsão de vazão, otimização da operação de reservatórios, algoritmo evolucionário, previsão quantitativa de chuva, AMANDA.

\section{INTRODUÇÃO}

O sistema de produção de energia elétrica brasileiro utiliza a combinação de usinas hidrelétricas, centrais térmicas e outras fontes alternativas de geração de energia.

A potência instalada em usinas hidrelétricas representa cerca de $76 \%$ do total, $21 \%$ corresponde as centrais térmicas e o restante $3 \%$ às fontes alternativas de energia, incluindo principalmente, a geração termonuclear, a geração eólica e a geração solar (ANEEL, 2006).

Esta forte dependência das hidrelétricas para produção de energia envolve importantes riscos de oferta, pois o insumo das usinas hidrelétricas é a vazão dos rios, que por sua vez é dependente do clima e sua variabilidade temporal e espacial. Para 
diminuir esta incerteza foi construído (a) Reservatórios que permitem a regularização intra e interanual, mas possuem limitação quanto a capacidade dentro de cada sub-sistema e a transmissão de energia entre sub-sistemas; (b) Sistemas térmicos que atuam de forma complementar e que são ligados quando as vazões são baixas e os reservatórios estão em níveis críticos.

Este sistema continua fortemente dependente do clima a curto e longo prazo para tomada de decisão quanto ao vertimento dos reservatórios, o uso dos sistemas térmicos que possuem maiores custos de operação e a própria segurança da barragem a eventos extremos.

O aumento da eficiência na geração hidrelétrica representa importantes benefícios para o país incluindo a diminuição dos riscos de racionamentos de energia, o aumento na segurança futura da diversificação e conservação de fontes de energia, o menor consumo atual de fontes não renováveis, como as utilizadas nas usinas térmicas, e a diminuição dos custos operacionais de conjunto.

O objetivo deste artigo foi avaliar os benefícios da utilização de previsões de vazão de afluência na operação de um reservatório com dois usos conflitantes: a geração de energia e o controle de cheias. A metodologia foi aplicada a um problema baseado nos dados do reservatório de Três Marias, no rio São Francisco, Minas Gerais.

A previsão de vazão afluente a reservatórios pode ser útil para reduzir esses conflitos. Porém, os benefícios da previsão dependem da eficiência dos modelos de previsão e da forma como a informação da previsão é incorporada na tomada de decisão sobre a operação (Yao e Georgakakos, 2001).

No trabalho anterior (Bravo et al., in press) foi apresentada uma metodologia de otimização de regras de operação com base em previsões de vazão. Nesse trabalho essa metodologia é utilizada para avaliar os benefícios da previsão de vazão de curto e longo prazo na operação do reservatório.

\section{PREVISÃO HIDROLÓGICA}

A previsão de vazão é a estimativa de valores de vazão para um ou mais intervalos de tempo específicos no futuro. O intervalo de tempo no futuro, que define a antecedência das previsões, recebe o nome de horizonte de previsão. Tipicamente, a previsão de vazão pode ser realizada para curto ou longo prazo. A previsão de curto prazo é realizada com antecedência de horas ou alguns dias, enquanto que a previsão de longo prazo é realizada com antecedência de alguns meses (até 9 meses) (Georgakakos e Krysztofowicz, 2001).

Por sua vez, a freqüência de previsão define o período de tempo no qual são emitidos novos dados de previsão. Assim por exemplo, uma previsão de vazão que se estende por 3 dias e que é repetida a cada dia tem uma freqüência diária e um horizonte de 3 dias. Neste trabalho esta previsão será denominada resumidamente 1-3 (freqüência-horizonte). Da mesma forma, uma previsão 7-12 representa uma previsão de vazão afluente de 12 dias à frente (horizonte) que é gerada a cada 7 dias (freqüência).

\section{BENEFÍCIOS DA PREVISÃO DE VAZÃO}

Considerando a importância do assunto, não são muitos os estudos de avaliação dos benefícios econômicos da utilização da previsão de vazão na operação de reservatórios (Yeh et al., 1982; Mishalani e Palmer, 1988; Georgakakos, 1989; Georgakakos et al., 1998; Yao e Georgakakos, 2001; Hamlet et al., 2002; Maurer e Lettenmaier, 2004).

A partir da década de 80 foram iniciadas, embora esporadicamente, diversas pesquisas que tentaram avaliar os benefícios da previsão de vazão afluente na operação de reservatórios. Assim, Yeh et al. (1982) se apresentaram como os primeiros em tentar dar uma resposta às perguntas: 1) qual é o valor econômico da informação de previsão para a operação de reservatórios? 2) quais devem ser os graus de precisão das previsões para obter esses benefícios? Estes autores estabeleceram as bases das análises que seriam feitas posteriormente, e avaliaram os benefícios das previsões de longo prazo com diferentes horizontes e graus de incerteza, considerando um intervalo de tempo mensal na simulação. Yeh et al. (1982), assim como Mishalani e Palmer (1988), demonstraram que os benefícios da previsão perfeita de vazão na operação de reservatórios dependem dos horizontes de previsão, isto é, maiores benefícios são obtidos para maiores horizontes de previsão.

Outros aspectos também influenciam o benefício potencial das previsões de vazão na operação de reservatórios. Maurer e Lettenmaier (2004) analisaram os benefícios da previsão perfeita de vazão na operação de reservatórios com diferentes capacidades de regularização. Os autores utilizaram o quociente entre o volume útil do sistema e o volume 
afluente médio anual para caracterizar os diferentes reservatórios ou sistemas de reservatórios. Os resultados obtidos mostraram que o beneficio do uso da previsão perfeita de vazão de longo prazo na operação de reservatórios tende a aumentar na medida em que as dimensões do sistema de reservatórios (ou de um único reservatório) diminuem.

\section{INTEGRAC̣ÃO DE MODELOS DE PREVISÃO E OPERAÇÃO DE UM RESERVATÓRIO}

A estrutura de integração de modelos climatológicos, hidrológicos e de operação em tempo real de reservatórios utilizada nesse trabalho é apresentada na Figura 1.

Observa-se nessa figura que a estrutura considera três etapas na definição da operação em tempo real de um reservatório. Na primeira etapa são obtidas as previsões quantitativas de chuva por downscaling das previsões do modelo global do CPTEC/INPE com o modelo meteorológico regional ETA (Silva, 2005).

A segunda etapa utiliza uma combinação de dados de precipitação observada e prevista para alimentar o modelo hidrológico MGB-IPH e gerar as previsões de vazão com uma antecedência $\mathrm{H}$, conforme apresentado em Tucci et al. (2004), Collischonn et al (2005a), Collischonn et al (2005b) e Silva (2005). Dessa forma, as previsões de vazão obtidas através dessa metodologia são denominadas previsões com modelos neste trabalho.

Por fim, na terceira etapa é utilizado o modelo AMANDA (Bravo et al., 2005; Bravo, 2006; Bravo et al., in press) na simulação da operação em tempo real com base na previsão de vazão. O modelo AMANDA utiliza os dados das características do reservatório, demandas, restrições e as previsões de vazão previamente geradas. A operação definida por esse modelo é baseada em uma curva-guia para controle de cheias que foi previamente definida com base em informações da serie histórica de vazões de afluência observadas. Essa curva-guia foi obtida por um processo de otimização com base em um período da série histórica e considerando previsões perfeitas de vazão (vazões observadas como previsão), conforme apresentado em Bravo et al. (in press).

O modelo AMANDA define a operação do reservatório (vazões turbinadas e vertidas) no dia em que recebe os dados de previsão para os próximos intervalos de tempo até receber os novos dados de previsão.

\section{METODOLOGIA}

O método de estimativa dos benefícios do uso de previsões de vazão afluente ao reservatório é baseado em simulações matemáticas do balanço hídrico de um reservatório com dois usos conflitantes: a geração de energia e o controle de cheias.

A simulação da operação do reservatório foi realizada com base em dois tipos de modelos para avaliar os benefícios da previsão. Um modelo de operação sem previsão e outro com previsão de vazão afluente. Regras de operação simples, na forma de curvas-guia para controle de cheias lineares, foram utilizadas nos casos de operação com e sem previsão de vazões afluentes. As curvas-guia foram otimizadas através de uma técnica de parametrização, simulação e otimização utilizando um algoritmo evolucionário, conforme apresentado em Bravo et al. (2006) no caso da operação sem previsão e em Bravo et al. (in press) no caso da operação com previsão.

As Figuras 2 e 3 apresentam a metodologia utilizada na otimização das curvas-guia para controle de cheias sem e com previsão, respectivamente. Observa-se nessas figuras que a única diferença se encontra no modelo de simulação da operação. Quando otimizada uma curva-guia sem previsão é utilizado o modelo de balanço hídrico (descrito como uma componente do modelo AMANDA em Bravo et al., in press) na operação. Por sua vez, quando otimizada uma curva-guia com previsão é utilizado o modelo AMANDA, o qual considera as previsões de vazão durante a operação do reservatório.

Uma vez obtidas as curvas-guia otimizadas com e sem previsão no período de otimização, elas podem ser utilizadas na operação em tempo real no mesmo período ou em outro período diferente. Nesse caso, somente o modelo de balanço (operação em tempo real sem previsão) ou o modelo AMANDA (operação em tempo real com previsão) são utilizados, conforme apresentado na Figura 4.

\section{APLICAC̣ÃO DA METODOLOGIA}

Duas abordagens foram utilizadas para avaliar os benefícios da previsão de vazão segundo a metodologia previamente apresentada: 


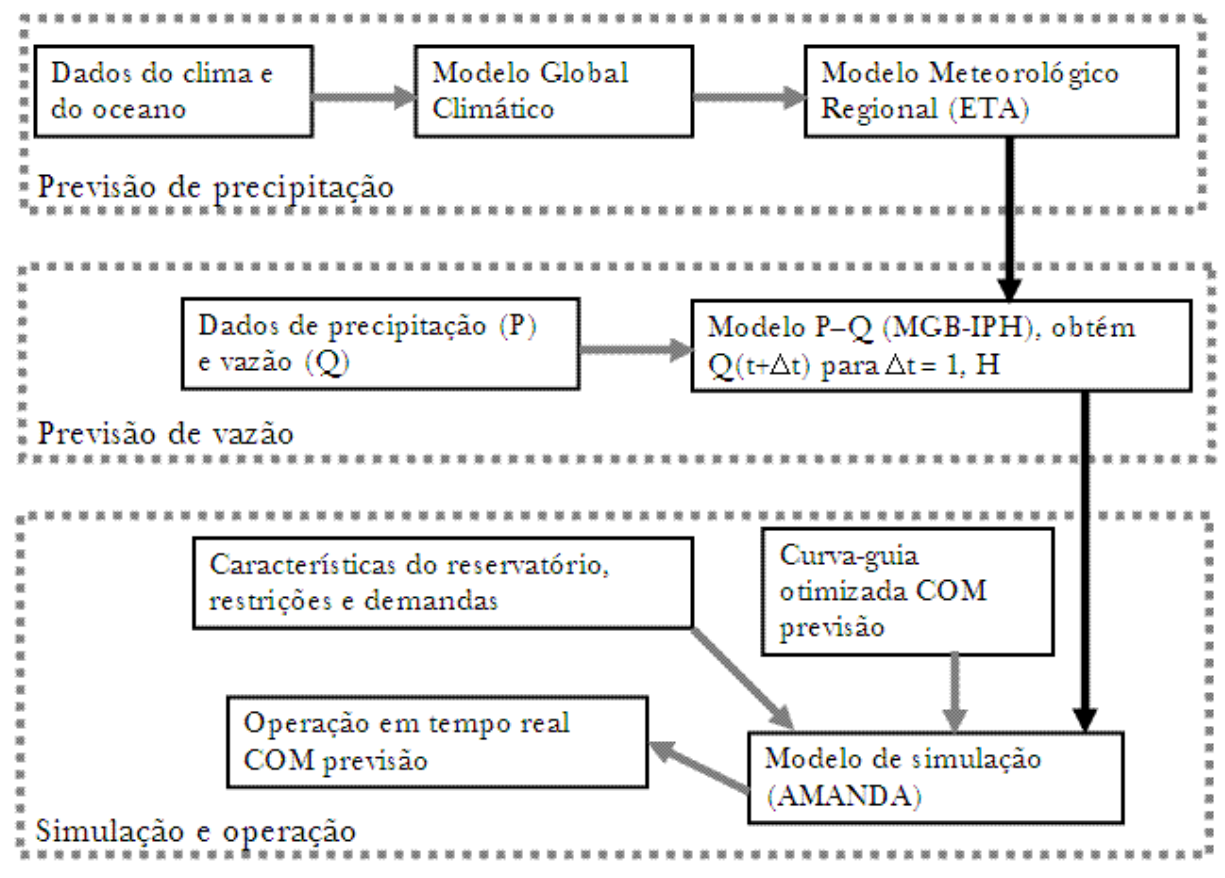

Figura 1 - Estrutura de integração de modelos climatológicos, hidrológicos e de operação de reservatórios na operação em tempo real de um reservatório com base na previsão de vazão.

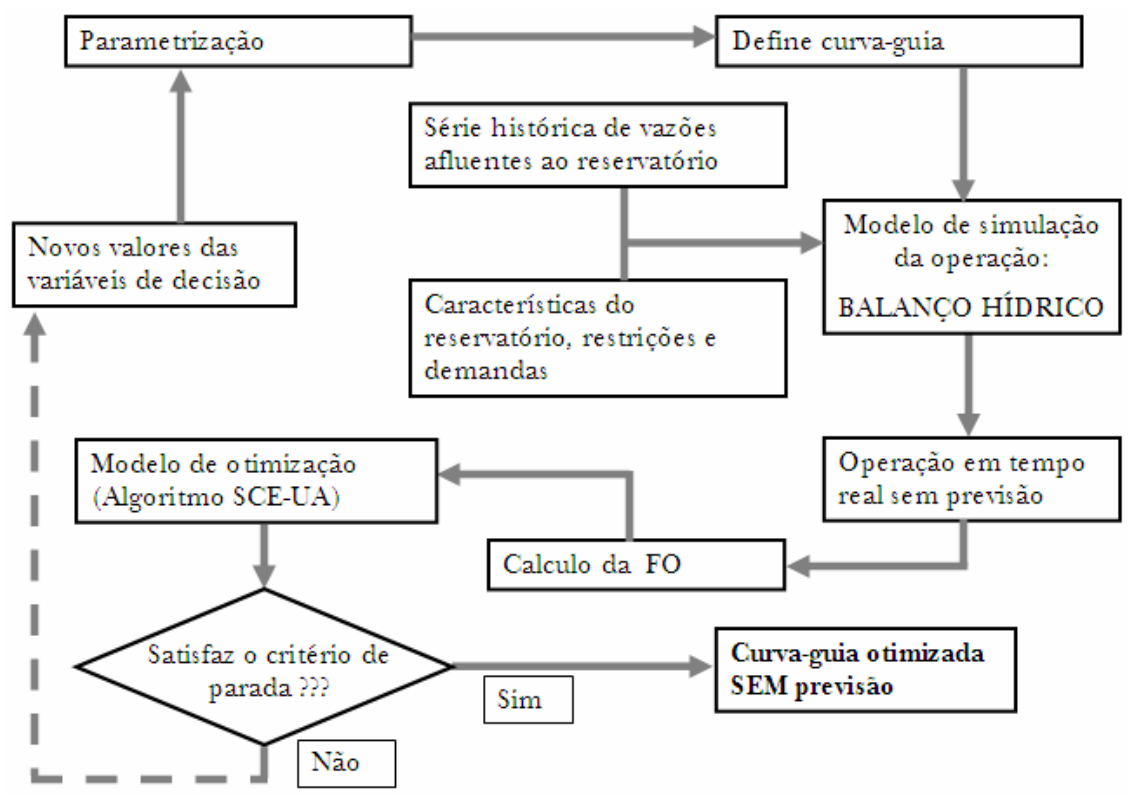

Figura 2 - Metodologia de parametrização, simulação e otimização utilizada na definição de curvas-guia otimizadas para a operação em tempo real sem previsão de um reservatório. 


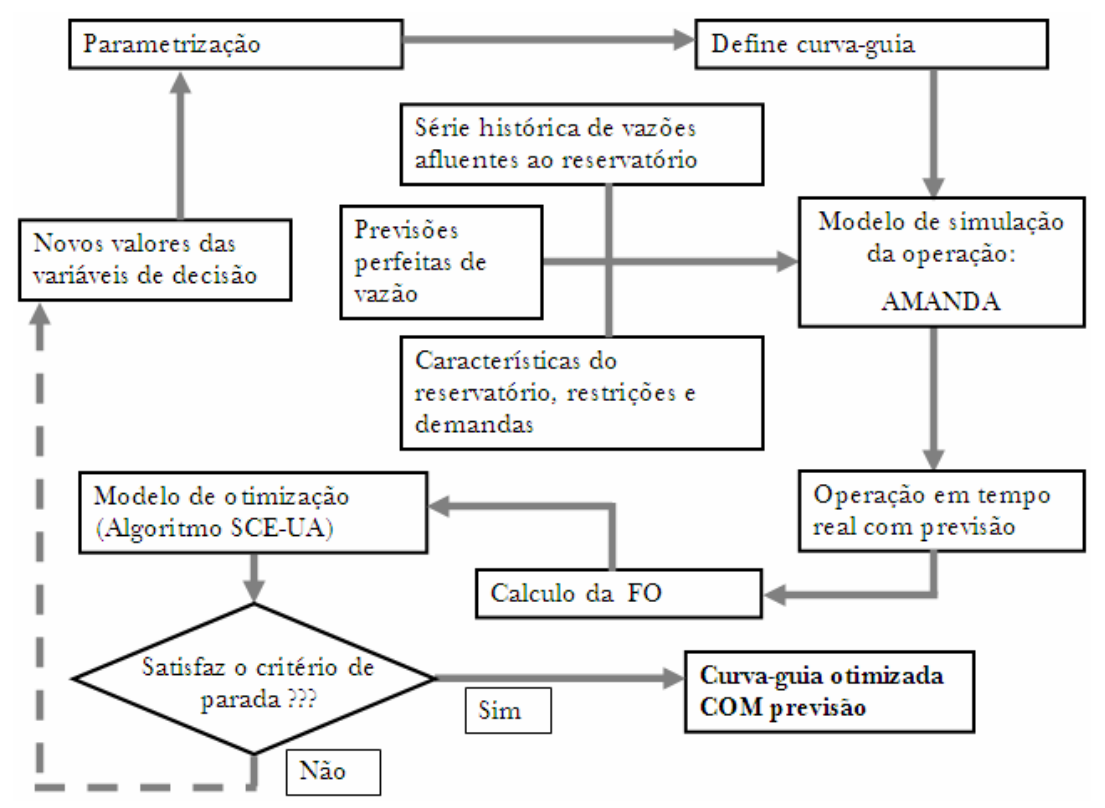

Figura 3 - Metodologia de parametrização, simulação e otimização utilizada na definição de curvas-guia otimizadas para a operação em tempo real com previsão de um reservatório.

- Avaliação dos benefícios da previsão perfeita de vazão. Esses benefícios representam os patamares superiores que poderiam ser obtidos num caso ideal (tratam-se de previsões sem erros), e são úteis para comparação e análise;

- Avaliação dos benefícios do uso de previsões de vazão de curto prazo obtidas a partir de previsões quantitativas de chuvas (aqui denominadas, previsões com modelos). Estas previsões foram calculadas em Silva (2005).

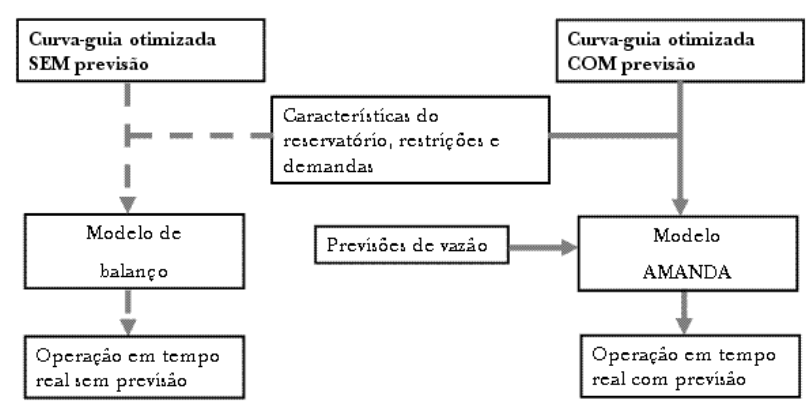

Figura 4 - Metodologia de operação em tempo real com (direita) e sem (esquerda) previsão de vazão.

\section{Dados do estudo de caso}

Os dados utilizados neste trabalho são os mesmos apresentados no primeiro trabalho da seqüência (Bravo et al., in press) e isso inclui tanto as informações hidrológicas e de restrição da operação do reservatório como a função-objetivo utilizada no processo de otimização. É importante ressaltar que foi considerado que o reservatório possui apenas, dois usos: a geração de energia e o controle de cheias.

O período utilizado na avaliação dos benefícios da previsão perfeita de vazão inclui toda a série, isto é, os 71 anos de dados diários disponibilizados. Por sua vez, na avaliação dos benefícios das previsões com modelos foram utilizados os dados correspondentes ao período de seis anos que inicia em janeiro de 1996 e finaliza em dezembro de 2001. Esse período foi escolhido para as análises, principalmente pela disponibilidade de previsões de vazão de curto prazo a partir de um trabalho prévio (Silva, 2005).

A metodologia de previsão de vazão de curto prazo, utilizada por este autor, foi baseada no uso de um modelo hidrológico distribuído (Collischonn e Tucci, 2001) e dados de chuva observada e prevista.

Os dados observados de chuva nos postos pluviométricos foram utilizados como dados de entrada para o modelo hidrológico até o dia anteri- 
or ao início da previsão. A partir do primeiro dia da previsão foram utilizados os dados de previsão de chuva do modelo regional ETA, até o décimo dia de previsão. A partir do décimo primeiro dia de previsão considerou-se que a chuva é nula em todas as bacias. Dados de vazão observada em diferentes postos fluviométricos também foram utilizados para o procedimento de atualização do modelo hidrológico (Collischonn et al., 2005b).

As previsões foram iniciadas sempre às quartas feiras, estendendo se por 14 dias, dos quais foram utilizados os primeiros 12 neste trabalho.

Na Figura 5 são apresentados os resultados médios obtidos por este autor, no período 19962001, considerando uma previsão com freqüência de sete dias e para os primeiros sete dias do horizonte. Na ordenada dos diferentes gráficos apresentados na Figura 5 se encontra a vazão média de sete dias, denominada pelo autor de "vazão semanal".

\section{Avaliação dos benefícios da previsão perfeita de vazão}

Para avaliar o potencial benefício das previsões de vazão na operação do reservatório, consideraram-se as vazões afluentes observadas como previsões perfeitas de vazão. Nessa avaliação, a série disponível de vazões observadas (1931 a 2001) foi dividida em dois períodos: P31-64 com dados de 01/01/1931 a 12/09/1964 e P64-01 com dados de 13/09/1964 a $28 / 11 / 2001$

Os dois períodos (P31-64 e P64-01) foram utilizados para otimizar a curva-guia de operação do reservatório sem previsão de vazão e com base na previsão perfeita de vazões. $\mathrm{Na}$ operação com base na previsão de vazão foram otimizadas sete curvasguia para cada período de dados, de acordo com sete diferentes combinações de horizonte e freqüência de previsão, como é apresentado em forma mais detalhada adiante no texto.

As curvas-guia otimizadas considerando a operação sem previsão foram utilizadas como base de comparação para avaliar os benefícios da previsão. Cada curva-guia otimizada sem previsão e com base na previsão perfeita de vazão foi utilizada para simular a operação em tempo real do reservatório nos dois períodos.

Essa abordagem permitiu avaliar os benefícios da previsão perfeita de vazão em quatro diferentes situações, dadas as diferenças existentes entre as magnitudes dos eventos desses dois períodos (no período P31-64 a magnitude do maior evento não superou os $4500 \mathrm{~m}^{3} \cdot \mathrm{s}^{-1}$, em quanto que o período
P64-01 é mais úmido, existindo seis eventos que superaram esse valor):

1. Simulação da operação do reservatório no período P31-64 com as curvas-guia definidas no mesmo período. Nesse caso, os benefícios da previsão perfeita de vazão são avaliados num período relativamente seco;

2. simulação da operação do reservatório no período P64-01 com as curvas-guia definidas no período P31-64. Dessa forma são identificados os benefícios da previsão perfeita de vazão quando ocorrem cheias maiores às esperadas implicitamente pela adoção de uma curva-guia;

3. simulação da operação do reservatório no período P64-01 com as curvas-guia definidas no mesmo período. Nesse caso, os benefícios da previsão perfeita de vazão são avaliados num período mais úmido, com uma maior variabilidade das magnitudes dos eventos;

4. simulação da operação do reservatório no período P31-64 com as curvas-guia definidas no período P64-01. Nesse caso, são identificados os benefícios da previsão perfeita de vazão quando ocorrem cheias inferiores às esperadas implicitamente pela adoção de uma curva-guia.

A comparação dos resultados obtidos na simulação da operação do reservatório sem previsão e com base na previsão foi feita, em todos os casos, em termos de potência média. Posteriormente, esse valor foi transformado para benefícios econômicos, admitindo se um valor monetário para o MW.h.

A comparação dos resultados também foi feita em termos de magnitude e duração das quebras da restrição relativa ao nível da água no reservatório para evitar inundações em locais a montante. A magnitude é a diferença entre o nível da água máximo atingido durante a simulação e a cota limite imposta pela restrição. A duração é o número de dias em que o nível da água permanece acima da cota limite.

\section{Otimização da curva-guia sem previsão}

Após alguns experimentos iniciais constatou-se que a curva-guia para o estudo de caso poderia ser satisfatoriamente definida por seis pontos no período P31-64 e por dez pontos no período P64-01. Esses experimentos consistiram em repetir o processo de otimização para um número crescente de pon- 

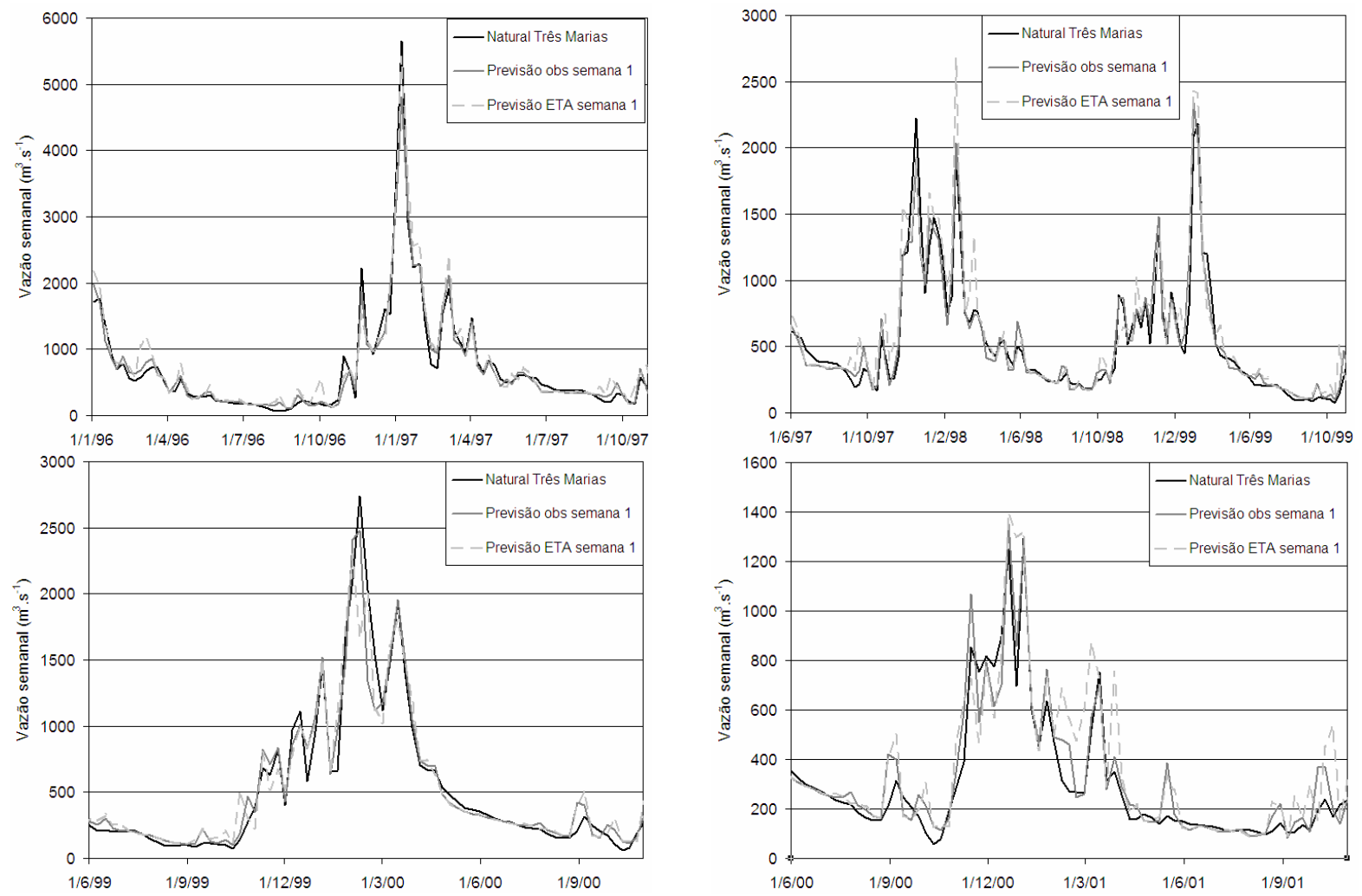

Figura 5 - Previsões de vazão semanal com uma semana de antecedência para Três Marias no período de janeiro de 1996 a novembro de 2001 sendo a linha preta: vazão natural; linha cinza: previsão de vazão baseada na chuva observada; linha cinza tracejada: previsão de vazão baseada na previsão de chuva do modelo ETA (Silva. 2005).

pontos de quebre (variáveis de decisão) e verificar o valor encontrado da função-objetivo. A partir de um determinado número (seis pontos de quebre no período P31-64 e dez no período P64-01) o incremento no valor da função-objetivo com um número maior de variáveis de decisão era insignificante e, em conseqüência, esse era o número de pontos de quebre adotados. Maiores detalhes podem ser encontrados em Bravo et al. (2006).

Os dois períodos (P31-64 e P64-01) foram utilizados para otimizar a curva-guia de operação do reservatório sem previsão de vazão, de acordo com a metodologia previamente descrita.

A curva-guia de operação do reservatório, sem previsão de vazão, otimizada com base na vazão afluente do período P31-64 foi denominada SP3164. Esta curva-guia foi parametrizada em segmentos de retas ligando seis pontos. As datas de cada ponto foram pré-definidas e as cotas para cada um dos seis pontos foram otimizadas, admitindo-se a busca no intervalo de cotas entre $559,00 \mathrm{~m}$ e $572,45 \mathrm{~m}$, conforme a Tabela 1 .
Tabela 1 - Datas e cotas para otimização da curva-guia com dados de vazão de 1931 a 1964.

\begin{tabular}{|l|l|l|}
\hline Data & $\begin{array}{l}\text { Cota limite } \\
\text { inferior }(\mathrm{m})\end{array}$ & $\begin{array}{l}\text { Cota limite } \\
\text { superior }(\mathrm{m})\end{array}$ \\
\hline $15 / 01$ & 559,00 & 572,45 \\
\hline $14 / 02$ & 559,00 & 572,45 \\
\hline $16 / 03$ & 559,00 & 572,45 \\
\hline $15 / 04$ & 559,00 & 572,45 \\
\hline $15 / 05$ & 559,00 & 572,45 \\
\hline $11 / 12$ & 559,00 & 572,45 \\
\hline
\end{tabular}

A curva-guia de operação do reservatório, sem previsão de vazão, otimizada com base na vazão afluente do período P64-01 se denominou SP64-01. Esta curva-guia foi parametrizada em segmentos de retas ligando dez pontos. As datas de cada ponto foram pré-definidas e as cotas para cada um dos dez pontos foram otimizadas, admitindo-se a busca no intervalo de cotas entre $559,00 \mathrm{~m}$ e $572,45 \mathrm{~m}$, conforme a Tabela 2 . 
Tabela 2 - Datas e cotas para otimização da curva-guia com dados de vazão de 1964 a 2001.

\begin{tabular}{|l|l|l|}
\hline Data & $\begin{array}{l}\text { Cota limite } \\
\text { inferior }(\mathrm{m})\end{array}$ & $\begin{array}{l}\text { Cota limite } \\
\text { superior }(\mathrm{m})\end{array}$ \\
\hline $15 / 01$ & 559,00 & 572,45 \\
\hline $14 / 02$ & 559,00 & 572,45 \\
\hline $16 / 03$ & 559,00 & 572,45 \\
\hline $15 / 04$ & 559,00 & 572,45 \\
\hline $15 / 05$ & 559,00 & 572,45 \\
\hline $30 / 05$ & 559,00 & 572,45 \\
\hline $29 / 06$ & 559,00 & 572,45 \\
\hline $28 / 08$ & 559,00 & 572,45 \\
\hline $11 / 11$ & 559,00 & 572,45 \\
\hline $11 / 12$ & 559,00 & 572,45 \\
\hline
\end{tabular}

\section{Otimização da curva-guia com previsão perfeita}

A otimização de curvas-guia com previsão perfeita de vazão seguiu um procedimento semelhante ao caso sem previsão, em conformidade com a metodologia.

Os dois períodos (P31-64 e P64-01) foram utilizados para otimizar a curva-guia de operação do reservatório com previsão perfeita de vazão. Foram otimizadas sete curvas-guia para cada período de dados, de acordo com as sete combinações de horizonte e freqüência apresentados na Tabela 3. Os nomes das curvas-guia geradas com e sem previsão também são apresentados nessa tabela.

Tabela 3 - Lista de curvas-guia otimizadas de acordo com a combinação de período de dados utilizado e de horizonte e freqüência da previsão.

\begin{tabular}{|l|l|l|}
\hline & $\mathbf{1 9 3 1 - 1 9 6 4}$ & $\mathbf{1 9 6 4 - 2 0 0 1}$ \\
\hline Sem previsão & SP31-64 & SP64-01 \\
\hline Previsão 1-7 & C1-7P31-64 & C1-7P64-01 \\
\hline Previsão 1-12 & C1-12P31-64 & C1-12P64-01 \\
\hline Previsão 1-30 & C1-30P31-64 & C1-30P64-01 \\
\hline Previsão 7-12 & C7-12P31-64 & C7-12P64-01 \\
\hline Previsão 7-30 & C7-30P31-64 & C7-30P64-01 \\
\hline Previsão 30-30 & C30-30P31-64 & C30-30P64-01 \\
\hline Previsão 30-60 & C30-60P31-64 & C30-60P64-01 \\
\hline
\end{tabular}

Para permitir uma comparação mais clara com as curvas-guia obtidas sem previsão, todas as curvas-guia otimizadas com previsão para o período de 1931 a 1964 têm seis pontos definindo os seg- mentos de retas, enquanto as curvas-guia otimizadas para o período de 1964 a 2001 têm dez pontos. Ainda, foram utilizadas as mesmas datas pré-definidas que no caso sem previsão.

As condições iniciais da simulação (volume do reservatório e vazão efluente no dia inicial da simulação) foram consideradas, em todos os casos, idênticas às utilizadas na operação sem previsão.

\section{Avaliação dos benefícios da previsão com modelos}

Os benefícios obtidos com a otimização da operação baseada na previsão perfeita de vazão de afluência ao reservatório representam patamares superiores que poderiam ser obtidos num caso ideal (tratam-se de previsões sem erros), e são úteis para comparação e análise. Na realidade, porém, as previsões com modelos apresentam erros. Os erros existentes nessas previsões são originados por erros na previsão da chuva e por erros na transformação da previsão de chuva em previsão de vazão. O modelo de transformação chuva-vazão é uma simplificação da realidade e em conseqüência, não alcança uma descrição de $100 \%$ do comportamento hidrológico da bacia. Da mesma forma, as previsões de chuvas não são perfeitas.

Previsões com modelos estavam disponíveis para a execução deste trabalho apenas no período de 1996 a 2001, e na combinação 7-12, isto é, previsões de vazão com horizonte de 12 dias e freqüência de 7 dias (Silva, 2005).

Para avaliar o benefício que pode ser esperado das previsões de vazão na operação de um reservatório em situações reais foi utilizada a estrutura metodológica de integração de modelos de previsão e operação em tempo real apresentada na Figura 1. Dessa forma, as previsões com modelos disponíveis no período 1996 a 2001 foram utilizadas para a operação do reservatório utilizando as curvas-guia obtidas a partir da previsão perfeita de vazão (C7-12P3164 e C7-12P64-01).

Os resultados foram comparados para o mesmo período com os resultados obtidos utilizando para a operação sem previsão as curvas-guia SP31-64 e SP64-01. Ainda para comparação e análise, previsões perfeitas de vazão também foram utilizadas na operação em tempo real do reservatório no período analisado.

A comparação foi feita em termos de potência média, posteriormente transformada para benefícios econômicos, admitindo se um valor monetário para o MW.h. A comparação dos resultados também foi feita em termos de magnitude e duração das quebras da restrição relativas aos níveis d'água no 
reservatório para evitar inundações em locais a montante. As condições iniciais da simulação (volume do reservatório e vazão efluente no dia inicial da simulação) foram consideradas, em todos os casos, idênticas às utilizadas na operação sem previsão.

É importante ressaltar que no caso da operação com base em previsões perfeitas de vazão o valor do parâmetro $\mathrm{H}_{\mathrm{seg}}$ do modelo AMANDA é igual a zero (Bravo et al, in press). Por sua vez, na simulação da operação do reservatório em tempo real com base nas previsões com modelos foi utilizado $\mathrm{H}_{\text {seg }}$ igual a $10 \mathrm{~cm}$, dado a existência de erros nessas previsões.

\section{RESULTADOS E DISCUSSÃO}

\section{Curvas-guia otimizadas na operação sem previsão}

A Figura 6 apresenta as duas curvas-guia obtidas pela otimização da operação sem previsão (SP31-64 e SP64-01). Observa-se que a curva-guia SP64-01 possui cotas inferiores às da curva-guia SP31-64 em quase todo o ano. Ainda existe uma marcada diferença nos volumes de espera durante o período úmido. Isso evidencia as grandes diferenças entre a magnitude dos maiores eventos de cada período. Enquanto no período 1931 a 1964 as maiores cheias não alcançaram os $4500 \mathrm{~m}^{3} \cdot \mathrm{s}^{-1}$, no período 1964 a 2001 ocorreram seis cheias que superaram esse valor, atingindo no maior desses eventos, uma vazão superior a $7000 \mathrm{~m}^{3} \cdot \mathrm{s}^{-1}$.

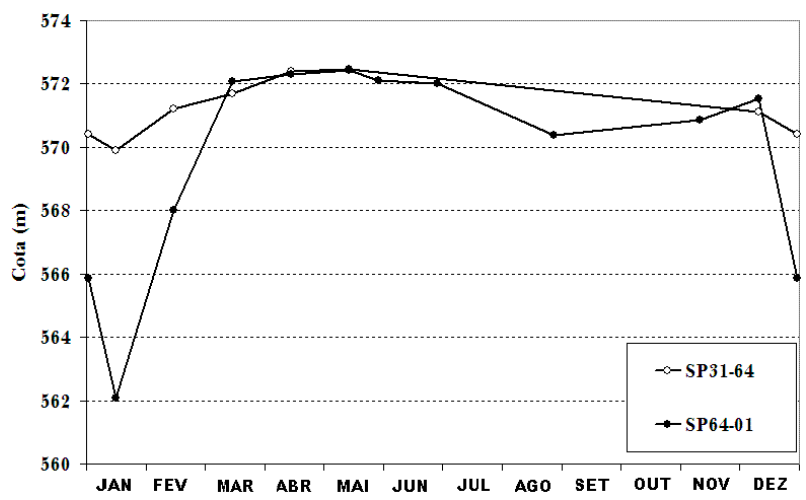

Figura 6 - Curvas-guia obtidas por otimização na situação de operação sem previsão nos períodos de 1931 a 1964 (SP31-64) e 1964 a 2001 (SP64-01).
Curvas-guia otimizadas na operação com previsão perfeita

Foram otimizadas 14 curvas-guia para a operação do reservatório com base na previsão perfeita, conforme a Tabela 3 .

As curvas-guia otimizadas com base nos dados de 1931 a 1964 e com base nos dados de 1964 a 2001 estão apresentadas nas Figuras 7 e 8. Observase que o horizonte da previsão e a freqüência de previsão têm um impacto grande na curva-guia.

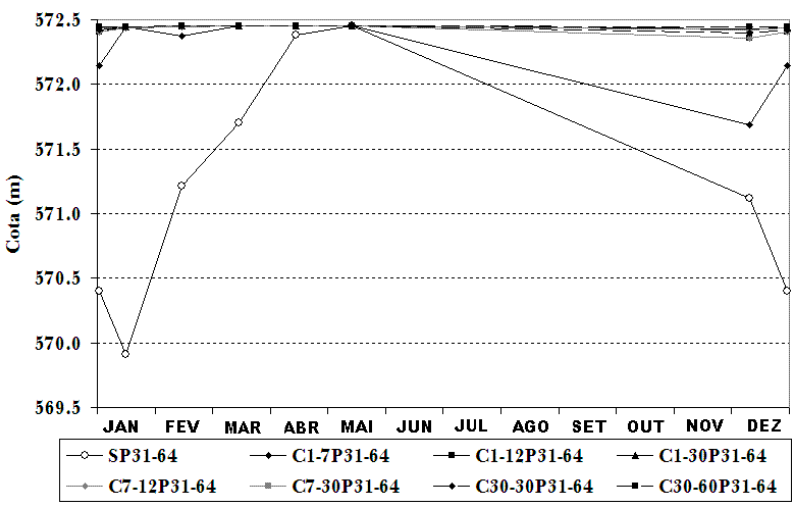

Figura 7 - Curvas-guia otimizadas com base no período de 1931 a 1964, para operação com previsão, comparadas à curva-guia otimizada para o caso de operação sem previsão com os dados do mesmo período (círculos brancos).

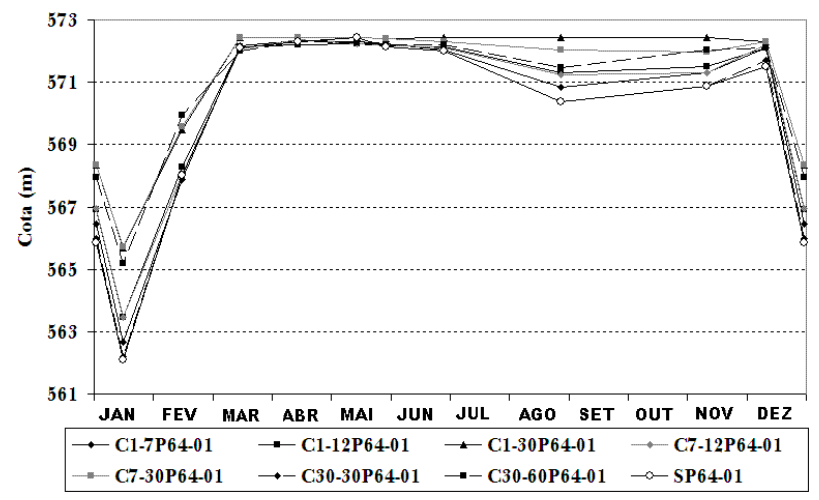

Figura 8 - Curvas-guia otimizadas com base no período de 1964 a 2001, para operação com previsão, comparadas à curva-guia otimizada para o caso de operação sem previsão com os dados do mesmo período (círculos brancos).

As Figuras 9 e 10 evidenciam as diferenças existentes nas curvas-guia para uma mesma freqüência e diversos horizontes de previsão (Figura 9) e 
para um mesmo horizonte e diversas freqüências de previsão (Figura 10). As curvas-guia otimizadas na situação de operação com base em previsões de vazão com horizontes mais curtos (ou maiores freqüências) são mais parecidas com a curva-guia otimizada para a operação sem previsão (apresentada com círculos brancos nessas figuras).

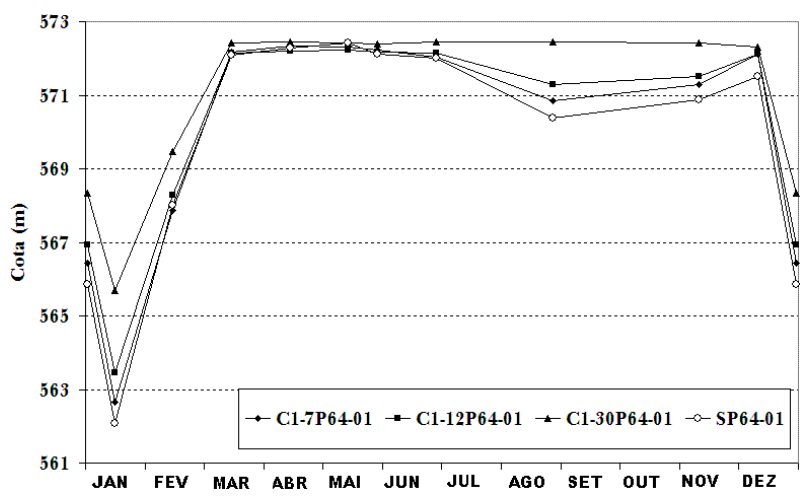

Figura 9 - Curvas-guia para uma mesma freqüência (1 dia) e diferentes horizontes de previsão (7, 12 e 30 dias). Curvas-guia otimizadas no período 1964 a 2001.

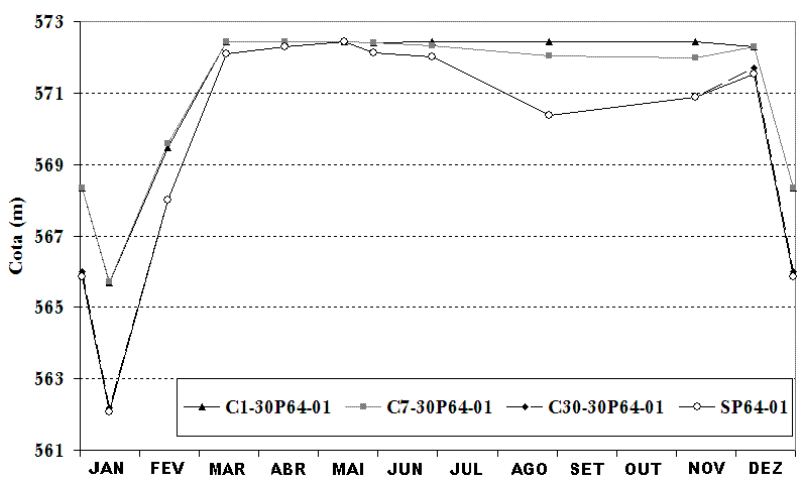

Figura 10 - Curvas-guia para um mesmo horizonte (30 dias) e diferentes freqüências de previsão (1, 7 e 30 dias). Curvas-guia otimizadas no período 1964 a 2001.

\section{Benefícios da previsão perfeita de vazão}

Na condição de operação sem previsão foram simuladas quatro situações diferentes, de acordo com a curva-guia e os dados utilizados. A primeira simulação foi realizada utilizando a curva-guia SP31-64 com os dados de vazão afluente do mesmo período. A segunda simulação foi realizada utilizando a curva-guia SP31-64 com os dados do período de 1964 a 2001. A terceira simulação foi realizada utilizando a curva-guia SP64-01 no período de 1931 a 1964 e finalmente, a quarta simulação foi realizada utilizando a curva-guia SP64-01 com os dados do período de 1964 a 2001. Os resultados em termos de benefícios econômicos totais e quebras de restrições são apresentados na Tabela 4. No cálculo dos benefícios econômicos foi considerado um valor monetário de 30 US\$/MW.h.

Tabela 4 - Benefícios econômicos totais e quebras de restrição na simulação de operação do reservatório sem previsão, segundo diferentes curvas-guia, em diferentes períodos da série histórica de vazões afluentes.

\begin{tabular}{|l|c|l|c|l|}
\hline \multirow{2}{*}{$\begin{array}{l}\text { Curva- } \\
\text { guia }\end{array}$} & \multicolumn{2}{|c|}{$\begin{array}{c}\text { Vazão afluente } \\
1931-1964\end{array}$} & \multicolumn{2}{c|}{$\begin{array}{c}\text { Vazão afluente } \\
1964-2001\end{array}$} \\
\cline { 2 - 5 } & $\begin{array}{c}\text { Benefício } \\
\text { (US\$/ano) }\end{array}$ & $\begin{array}{l}\text { Res- } \\
\text { tri- } \\
\text { ções }\end{array}$ & $\begin{array}{c}\text { Benefício } \\
\text { (US\$/ano) }\end{array}$ & $\begin{array}{l}\text { Res- } \\
\text { tri- } \\
\text { ções }\end{array}$ \\
\hline $\begin{array}{l}\text { SP31- } \\
64\end{array}$ & $\begin{array}{c}63,10 \\
\text { milhões }\end{array}$ & Não & $\begin{array}{c}66,78 \\
\text { milhões }\end{array}$ & Sim \\
\hline $\begin{array}{l}\text { SP64- } \\
01\end{array}$ & $\begin{array}{c}58,60 \\
\text { milhões }\end{array}$ & Sim & $\begin{array}{c}61,80 \\
\text { milhões }\end{array}$ & Não \\
\hline
\end{tabular}

$\mathrm{Na}$ condição de operação com previsão foram simuladas 28 situações diferentes, de acordo com a curva-guia e os dados utilizados. Estas simulações foram agrupadas em quatro grupos. No primeiro grupo, as simulações foram realizadas utilizando as curvas-guia otimizadas para operação com base em previsões perfeitas de vazão no período de 1931 a 1964 com os dados do mesmo período. No segundo grupo, as simulações foram realizadas utilizando as curvas-guia otimizadas no período 1931 a 1964 com os dados do período de 1964 a 2001. No terceiro grupo, as simulações foram realizadas utilizando as curvas-guia otimizadas para operação com base em previsões perfeitas de vazão no período de 1964 a 2001 com os dados do mesmo período. No quarto grupo, as simulações foram realizadas utilizando as curvas-guia otimizadas no período 1964 a 2001 com os dados do período de 1931 a 1964 . Os resultados em termos de incrementos nos benefícios econômicos com respeito à situação de operação sem previsão (coluna 5) e quebras de restrições (coluna 4) são apresentados nas Tabelas 5 a 8 . A comparação foi feita em termos de potência média, posteriormente transformada para benefícios econômicos. 
Tabela 5 - Resultados da simulação de operação em tempo real do reservatório com e sem previsão no período 1931 a 1964 (curvas-guia otimizadas para o mesmo período).

\begin{tabular}{|l|l|l|l|l|}
\hline $\begin{array}{l}\text { Previsão de } \\
\text { vazão }\end{array}$ & $\begin{array}{l}\text { Pot. Média } \\
(\text { MWmed })\end{array}$ & $\begin{array}{l}\Delta \text { Pot } \\
(\%)\end{array}$ & $\begin{array}{l}\text { Quebra } \\
\text { de } \\
\text { restr. }\end{array}$ & $\begin{array}{l}\Delta \text { Benefícios } \\
(\text { US\$/ano })\end{array}$ \\
\hline $\begin{array}{l}\text { Sem } \\
\text { previsão }\end{array}$ & 240,13 & - & Não & - \\
\hline Perfeita 1-7 & 241,48 & 0,56 & Não & 355 mil \\
\hline $\begin{array}{l}\text { Perfeita } \\
1-12\end{array}$ & 241,50 & 0,57 & Não & 361 mil \\
\hline $\begin{array}{l}\text { Perfeita } \\
1-30\end{array}$ & 241,50 & 0,57 & Não & 361 mil \\
\hline $\begin{array}{l}\text { Perfeita } \\
7-12\end{array}$ & 241,50 & 0,57 & Não & $361 \mathrm{mil}$ \\
\hline $\begin{array}{l}\text { Perfeita } \\
7-30\end{array}$ & 241,50 & 0,57 & Não & $361 \mathrm{mil}$ \\
\hline $\begin{array}{l}\text { Perfeita } \\
30-30\end{array}$ & 241,50 & 0,57 & Não & $361 \mathrm{mil}$ \\
\hline $\begin{array}{l}\text { Perfeita } \\
30-60\end{array}$ & 241,50 & 0,57 & Não & $361 \mathrm{mil}$ \\
\hline
\end{tabular}

Tabela 6 - Resultados da simulação de operação em tempo real do reservatório com e sem previsão no período 1964 a 2001 (curvas-guia otimizadas no período 1931-1964).

\begin{tabular}{|l|l|l|l|l|}
\hline $\begin{array}{l}\text { Previsão de } \\
\text { vazão }\end{array}$ & $\begin{array}{l}\text { Pot. Média } \\
(\text { MWmed })\end{array}$ & $\begin{array}{l}\Delta \text { Pot } \\
(\%)\end{array}$ & $\begin{array}{l}\text { Quebra } \\
\text { de } \\
\text { restr. }\end{array}$ & $\begin{array}{l}\Delta \text { Benefícios } \\
(\text { US\$/ano })\end{array}$ \\
\hline Sem previsão & 254,12 & - & Sim & - \\
\hline Perfeita 1-7 & 257,01 & 1,14 & Sim & $760 \mathrm{mil}$ \\
\hline Perfeita 1-12 & 257,06 & 1,16 & Sim & $773 \mathrm{mil}$ \\
\hline Perfeita 1-30 & 256,94 & 1,11 & Sim & $741 \mathrm{mil}$ \\
\hline Perfeita 7-12 & 257,08 & 1,17 & Sim & $779 \mathrm{mil}$ \\
\hline Perfeita 7-30 & 256,94 & 1,11 & Sim & $741 \mathrm{mil}$ \\
\hline Perfeita 30-30 & 257,01 & 1,14 & Sim & $761 \mathrm{mil}$ \\
\hline Perfeita 30-60 & 256,77 & 1,04 & Sim & $697 \mathrm{mil}$ \\
\hline
\end{tabular}

Observa-se em todos os casos que os incrementos dos benefícios na simulação da operação com base na previsão são sempre positivos e que variam em função do horizonte e da freqüência de previsão. Os maiores incrementos nos benefícios obtidos na simulação da operação no período de 1931 a 1964 utilizando as curvas-guia otimizadas no mesmo período representam, aproximadamente, $0,57 \%$ ou 360 mil dólares por ano. Na simulação da operação no período de 1964 a 2001 (utilizando as curvas-guia otimizadas no período 1964 a 2001), os maiores incrementos nos benefícios superam 8\%, representado em torno de 5,20 milhões de dólares por ano.

Tabela 7 - Resultados da simulação de operação em tempo real do reservatório com e sem previsão no período 1964 a 2001 (curvas-guia otimizadas no mesmo período).

\begin{tabular}{|l|l|l|l|c|}
\hline $\begin{array}{l}\text { Previsão de } \\
\text { vazão }\end{array}$ & $\begin{array}{l}\text { Pot. Média } \\
(\text { MWmed })\end{array}$ & $\begin{array}{l}\Delta \text { Pot } \\
(\%)\end{array}$ & $\begin{array}{l}\text { Quebra } \\
\text { de } \\
\text { restr. }\end{array}$ & $\begin{array}{c}\Delta \text { Benefícios } \\
(\text { US\$/ano) }\end{array}$ \\
\hline Sem previsão & 235,15 & - & Não & - \\
\hline Perfeita 1-7 & 241,29 & 2,61 & Não & $\begin{array}{c}1,61 \\
\text { milhões }\end{array}$ \\
\hline Perfeita 1-12 & 247,51 & 5,26 & Não & $\begin{array}{c}3,25 \\
\text { milhões }\end{array}$ \\
\hline Perfeita 1-30 & 254,92 & 8,41 & Não & $\begin{array}{c}5,20 \\
\text { milhões }\end{array}$ \\
\hline Perfeita 7-12 & 245,62 & 4,45 & Não & $\begin{array}{c}2,75 \\
\text { milhões }\end{array}$ \\
\hline Perfeita 7-30 & 255,14 & 8,50 & Não & $\begin{array}{c}5,25 \\
\text { milhões }\end{array}$ \\
\hline Perfeita 30-30 & 242,59 & 3,17 & Não & $\begin{array}{c}1,95 \\
\text { milhões }\end{array}$ \\
\hline Perfeita 30-60 & 254,58 & 8,26 & Não & $\begin{array}{c}5,11 \\
\text { milhões }\end{array}$ \\
\hline
\end{tabular}

Tabela 8 - Resultados da simulação de operação em tempo real do reservatório com e sem previsão no período 1931 a 1964 (curvas-guia otimizadas no período 1964-2001).

\begin{tabular}{|l|l|l|l|c|}
\hline $\begin{array}{l}\text { Previsão de } \\
\text { vazão }\end{array}$ & $\begin{array}{l}\text { Pot. Média } \\
(\text { MWmed })\end{array}$ & $\begin{array}{l}\Delta \text { Pot } \\
(\%)\end{array}$ & $\begin{array}{l}\text { Quebra } \\
\text { de } \\
\text { restr. }\end{array}$ & $\begin{array}{c}\Delta \text { Benefícios } \\
\text { (US\$/ano) }\end{array}$ \\
\hline Sem previsão & 222,97 & - & Sim & - \\
\hline Perfeita 1-7 & 227,64 & 2,09 & Não & $\begin{array}{c}1,22 \\
\text { milhões }\end{array}$ \\
\hline Perfeita 1-12 & 233,32 & 4,64 & Não & $\begin{array}{c}2,72 \\
\text { milhões }\end{array}$ \\
\hline Perfeita 1-30 & 240,56 & 7,89 & Não & $\begin{array}{c}4,62 \\
\text { milhões }\end{array}$ \\
\hline Perfeita 7-12 & 230,56 & 3,40 & Não & $\begin{array}{c}1,99 \\
\text { milhões }\end{array}$ \\
\hline Perfeita 7-30 & 240,43 & 7,83 & Não & $\begin{array}{c}4,59 \\
\text { milhões }\end{array}$ \\
\hline Perfeita 30-30 & 229,99 & 3,15 & Não & $\begin{array}{c}1,84 \\
\text { milhões }\end{array}$ \\
\hline Perfeita 30-60 & 239,75 & 7,52 & Não & $\begin{array}{c}4,41 \\
\text { milhões }\end{array}$ \\
\hline
\end{tabular}


Esses resultados indicam que a consideração da previsão na operação do reservatório apresenta maiores benefícios naqueles períodos onde existe uma maior diferença entre os eventos implicitamente considerados como de projeto na adoção da curva-guia para controle de cheias e os restantes eventos do período.

As Figuras 11 e 12 apresentam a influência que a freqüência e o horizonte da previsão têm nos benefícios obtidos na simulação da operação com base na previsão de vazão afluente.

Observa-se nessas figuras que os benefícios da previsão, para uma mesma freqüência, aumentam na medida em que se utilizam previsões com maiores horizontes, como era esperado. Contudo, considerando um horizonte de 30 dias e utilizando previsões com freqüência de 30 dias (mensal), os benefícios obtidos representam apenas $50 \%$ dos benefícios que podem ser obtidos se utilizada uma freqüência diária ou semanal.

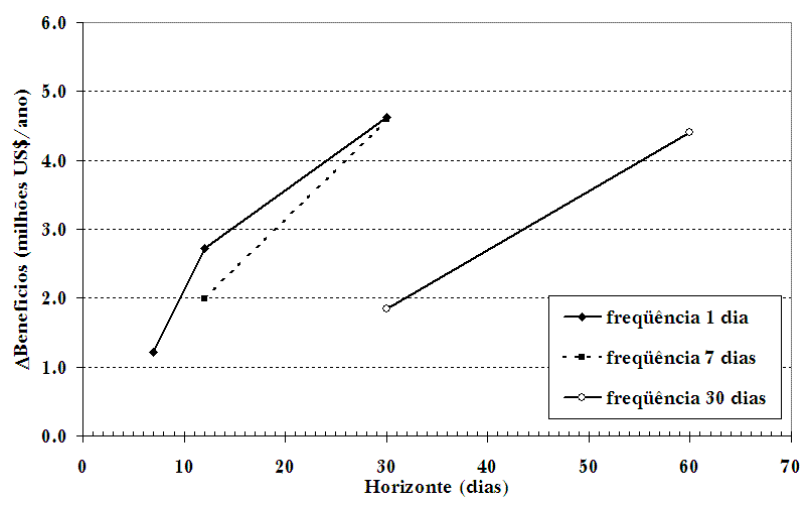

Figura 11 - Influência do horizonte de previsão e da freqüência de previsão nos benefícios obtidos na simulação da operação em tempo real com base na previsão. Resultados no período 1931 a 1964 utilizando as curvas-guia otimizadas no período 1964 a 2001.

Os benefícios são praticamente os mesmos para horizontes de 30 dias considerando uma freqüência diária ou semanal. Na medida em que o horizonte diminui as diferenças nos benefícios se tornam notórias. Assim, no caso de uma freqüência diária ou semanal existe uma diferença nos benefícios em torno de 0,80 milhões de dólares por ano (Figura 11) quando são utilizadas previsões com 12 dias de horizonte.

Ocorrem quebras de restrição em todas as simulações do período de 1964 a 2001 utilizando as curvas-guia otimizadas no período de 1931 a 1964 (veja a Tabela 6).

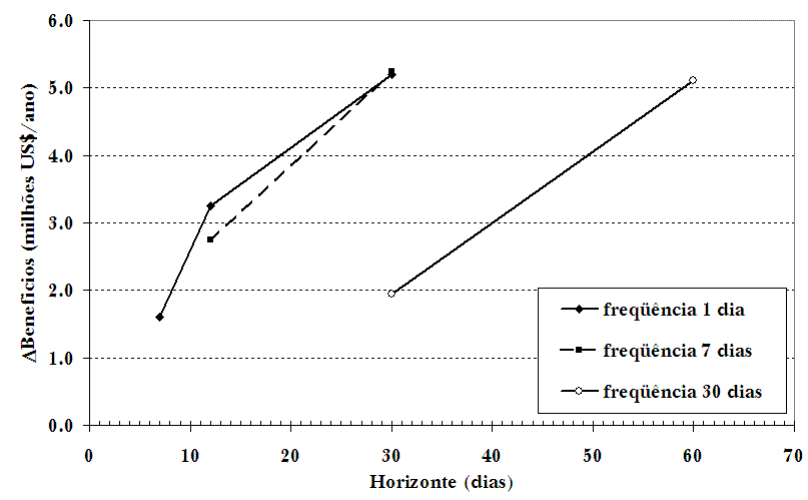

Figura 12 - Influência do horizonte de previsão e da freqüência de previsão nos benefícios obtidos na simulação da operação em tempo real com base na previsão. Resultados no período 1964 a 2001 utilizando as curvas-guia otimizadas no mesmo período.

As quebras de restrição em cada um dos casos simulados foram analisadas em termos de magnitude e duração. A magnitude é a diferença entre o nível da água máximo atingido durante a simulação e a cota limite imposta pela restrição $(572,50 \mathrm{~m})$. A duração é o número de dias em que o nível da água permanece acima da cota limite.

A análise das quebras de restrição no período 1964 a 2001 utilizando as curvas-guias otimizadas no período 1931 a 1964 mostra que, no caso da previsão perfeita 7-12 existiu o mesmo número de quebras de restrição que na operação sem previsão. Porém, analisando as quebras de restrição mais severas acontecidas nos quatro eventos de maiores magnitudes desse período (fevereiro de 1979, fevereiro de 1983, fevereiro de 1992 e janeiro de 1997) se percebe que apenas em um dos eventos o nível máximo alcançado na operação com previsão foi superior ao caso sem previsão. Nos restantes três eventos os níveis máximos alcançados com previsão foram sempre inferiores em comparação ao caso sem previsão. O mesmo acontece com a duração das quebras de restrição. Já com o aumento dos horizontes de previsão, o número de quebras de restrição se reduziu a só duas, com os menores valores de magnitude e duração das mesmas.

Por fim, como exemplo, nas Figuras 13 e 14 se apresentam os cotagramas das simulações de operação em tempo real com base na previsão perfeita 1-30 e os cotagramas correspondentes à operação em tempo real sem previsão. A Figura 13 apresenta a simulação da operação para o período 1931-1964 
utilizando as curvas-guia otimizadas do mesmo período. Por sua vez, a Figura 14 apresenta a simulação da operação para o período 1964-2001 utilizando as curvas-guia otimizadas do mesmo período.

\section{Benefícios da previsão com modelos}

Em primeiro lugar, foram avaliados os benefícios da previsão com modelos utilizando a curvaguia C7-12P64-01. Os resultados foram comparados aos obtidos com a operação sem previsão, utilizando a curva-guia SP64-01, e com a operação com previsão perfeita, utilizando a curva-guia C7-12P64-01. Os resultados são apresentados na Tabela 9.

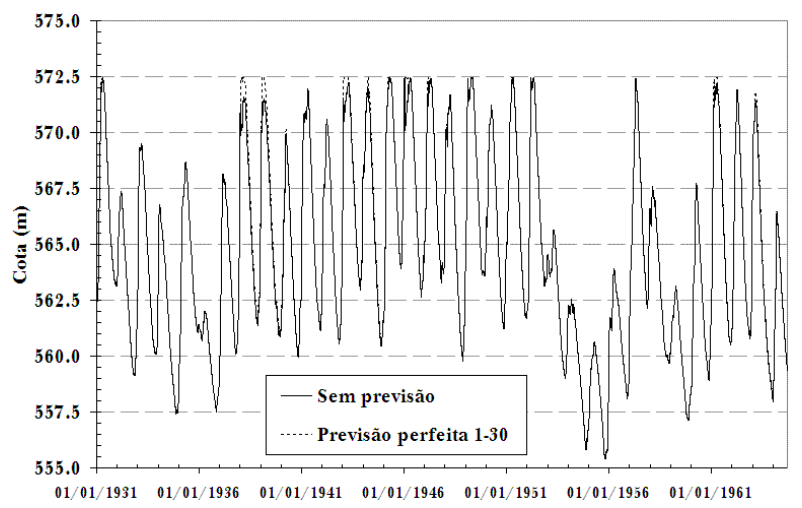

Figura 13 - Cotagramas do reservatório operado com previsão perfeita 1-30 e sem previsão no período de 1931 a 1964 (curvas-guia otimizadas para o mesmo período).

A operação sem previsão, usando a curvaguia SP64-01 resulta numa potência média de 221,3 MW. A operação com previsões perfeitas de vazão utilizando a curva-guia C7-12P64-01 resulta num acréscimo de 5,33\% na potência média, o que representa um incremento nos benefícios de 3,10 milhões de dólares por ano, considerando o custo de 30 dólares por MW.hora. A operação com previsão com modelos, utilizando a curva-guia C7-12P6401 resulta num acréscimo de 3,52\% na potência média, o que representa um benefício de 2,05 milhões de dólares por ano.

É importante ressaltar que, mesmo utilizando a previsão com modelos, não ocorreu nenhuma quebra de restrição. Isto significa que o incremento nos benefícios em mais de 2 milhões de dólares por ano (somente neste aproveitamento hidrelétrico) foi obtido sem comprometer a segurança da barragem e os outros usos do reservatório (controle de cheias).

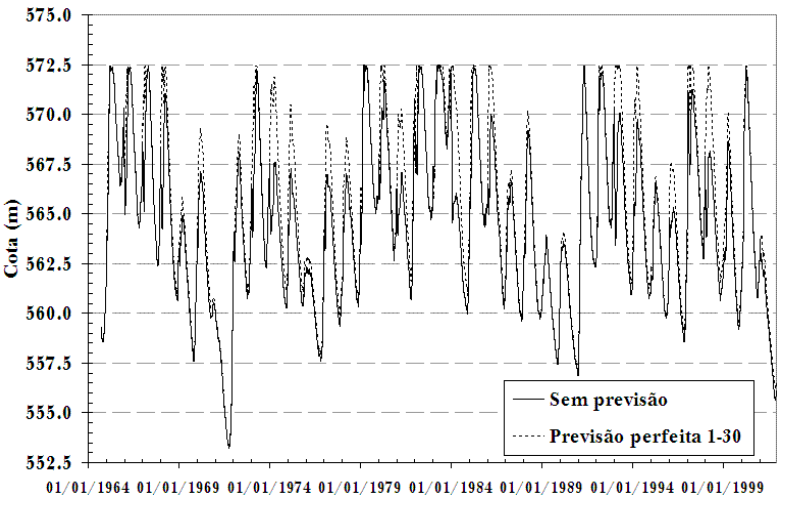

Figura 14 - Cotagramas do reservatório operado com previsão perfeita 1-30 e sem previsão no período de 1964 a 2001 (curvas-guia otimizadas para o mesmo período).

Tabela 9 - Resultados da simulação de operação do reservatório com e sem previsão no período janeiro de 1996 até novembro de 2001 (curvas-guia otimizadas para o período de 1964 a 2001).

\begin{tabular}{|l|l|l|l|c|}
\hline $\begin{array}{l}\text { Previsão } \\
\text { de vazão }\end{array}$ & $\begin{array}{l}\text { Pot.Média } \\
\text { (MWmed) }\end{array}$ & $\Delta \operatorname{Pot}(\%)$ & $\begin{array}{l}\text { Quebra } \\
\text { de } \\
\text { restri- } \\
\text { ção }\end{array}$ & $\begin{array}{c}\Delta \text { Benefícios } \\
\text { (US\$/ano) }\end{array}$ \\
\hline $\begin{array}{l}\text { Sem } \\
\text { previsão }\end{array}$ & 221,3 & - & Não & - \\
\hline $\begin{array}{l}\text { Previsão } \\
\text { perfeita }\end{array}$ & 233,1 & 5,33 & Não & $\begin{array}{c}3,10 \\
\text { milhões }\end{array}$ \\
\hline $\begin{array}{l}\text { Previsão } \\
\text { com } \\
\text { modelos }\end{array}$ & 229,1 & 3,52 & Não & $\begin{array}{c}2,05 \\
\text { milhões }\end{array}$ \\
\hline
\end{tabular}

Observa-se na Tabela 9, que o benefício obtido com a previsão com modelos representa cerca de dois terços do benefício que poderia ser obtido com previsões perfeitas de vazão.

Os cotagramas obtidos sob uma operação sem previsão, com base na previsão perfeita e com base na previsão com modelos são apresentados na Figura 15(a). Nesta figura é possível observar que os níveis da água são inferiores quando o reservatório é operado sem previsão de vazão.

Em segundo lugar, foram avaliados os benefícios da previsão com modelos utilizando a curvaguia C7-12P31-64. Os resultados foram comparados aos obtidos com a operação sem previsão, utilizando a curva-guia SP31-64, e com a operação com previsão perfeita de vazão, utilizando a curva-guia C7- 

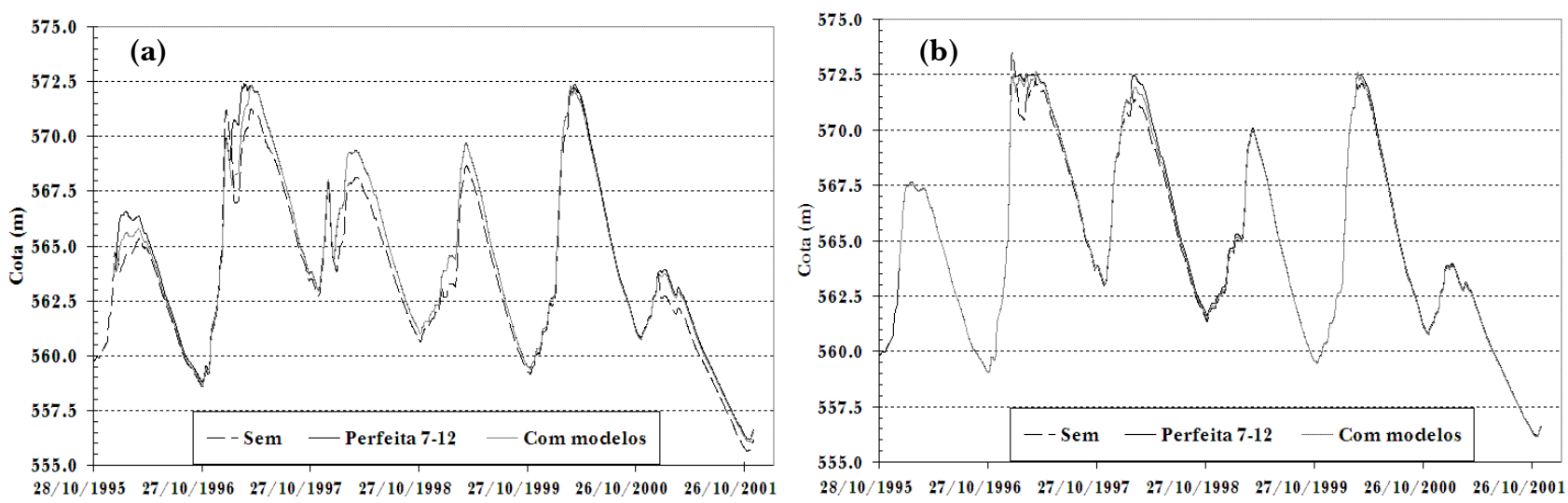

Figura 15 - Cotagramas do reservatório operado sem previsão; com previsão perfeita de vazão e com previsão com modelos no período de 1996 a 2001. (a) utilizando curvas-guia otimizadas no período de 1964 a 2001;

(b) utilizando curvas-guia otimizadas no período de 1931 a 1964.

12P31-64. Os resultados são apresentados na Tabela 10.

A operação sem previsão, usando a curvaguia SP31-64 resulta numa potência média de 240,8 MW. Este valor é superior ao obtido no caso anterior, usando a curva-guia SP64-01, porque a curva-guia SP31-64, otimizada para um período com menos eventos importantes de cheia, apresenta cotas mais altas do reservatório.

Tabela 10 - Resultados da simulação de operação do reservatório com e sem previsão no período janeiro de 1996 até novembro de 2001 (curvas-guia otimizadas para o período de 1931 a 1964).

\begin{tabular}{|l|l|l|l|c|}
\hline $\begin{array}{l}\text { Previsão } \\
\text { de vazão }\end{array}$ & $\begin{array}{l}\text { Pot.Média } \\
\text { (MWmed) }\end{array}$ & $\Delta \operatorname{Pot}(\%)$ & $\begin{array}{l}\text { Quebra } \\
\text { de } \\
\text { restri- } \\
\text { ção }\end{array}$ & $\begin{array}{l}\Delta \text { Benefícios } \\
\text { (US\$/ano) }\end{array}$ \\
\hline $\begin{array}{l}\text { Sem } \\
\text { previsão }\end{array}$ & 240,8 & - & Sim & - \\
\hline $\begin{array}{l}\text { Previsão } \\
\text { perfeita }\end{array}$ & 244,1 & 1,39 & Não & $\begin{array}{c}0,88 \\
\text { milhões }\end{array}$ \\
\hline $\begin{array}{l}\text { Previsão } \\
\text { com } \\
\text { modelos }\end{array}$ & 242,6 & 0,74 & Sim & $\begin{array}{c}0,47 \\
\text { milhões }\end{array}$ \\
\hline
\end{tabular}

A operação com previsão perfeita de vazão, utilizando a curva-guia C7-12P31-64 resulta num acréscimo de $1,39 \%$ na potência média, o que representa um incremento nos benefícios de 0,88 milhões de dólares por ano, considerando o custo de 30 dólares por MW.h. A operação com previsões com modelos, utilizando a curva-guia C7-12P31-64 resulta num acréscimo de $0,74 \%$ na potência média, o que representa um incremento nos benefícios de 0,47 milhões de dólares por ano.

Entretanto, as simulações da operação do reservatório sem previsão e com previsão com modelos apresentaram situações de quebra de restrição, conforme apresentado na Tabela 10, enquanto a simulação da operação com previsão perfeita de vazão não mostrou nenhuma quebra de restrição.

Os benefícios obtidos com a previsão são menores neste caso do que no caso anterior, mas mesmo assim se mantêm positivos.

Os cotagramas obtidos sob uma operação sem previsão, com base na previsão perfeita de vazão e com base na previsão com modelos são apresentados na Figura 15(b). Nesta figura é possível observar que os níveis da água são inferiores quando o reservatório é operado sem previsão de vazão. Observamse ainda as quebras de restrição, quando o nível é superior ao limite de 572,50 m.

As quebras de restrição em cada um dos casos simulados foram analisadas em termos de magnitude e duração. A magnitude é a diferença entre o nível da água máximo atingido durante a simulação e a cota limite imposta pela restrição. A duração é o número de dias em que o nível da água permanece acima da cota limite.

A Figura 16 apresenta as quebras de restrição observadas nas simulações descritas na Tabela 10. Observa-se nessa figura que na simulação de operação sem previsão utilizando a curva-guia SP3164 houve apenas uma quebra de restrição, que ocorreu em janeiro de 1997, com quase um metro de nível acima do máximo permitido. Na simulação de 
operação com previsão com modelos houve três quebras de restrição, mas todas elas com menos de $15 \mathrm{~cm}$. Além disso, a duração da quebra de restrição na simulação de operação sem previsão foi de 14 dias, ao passo que as quebras de restrição na simulação de operação com previsão com modelos tiveram apenas 1, 5 e 4 dias de duração (total de 10 dias).

Este resultado é importante porque indica que, embora ocorram algumas quebras de restrição quando o reservatório é operado com base a previsões com modelos, elas são apenas marginais, se comparadas ao que ocorreria em caso de operação sem previsão.

É importante ressaltar que o evento de janeiro de 1997 representa um dos mais críticos da série completa. Dito evento atingiu uma vazão afluente de pico superior a $6500 \mathrm{~m}^{3} . \mathrm{s}^{-1}$, sendo o segundo maior evento em termos de vazão de pico da série histórica.

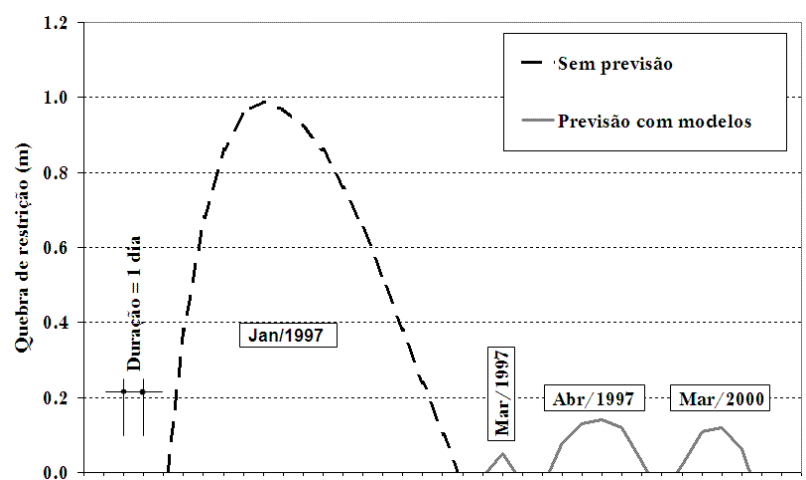

Figura 16 - Diferença entre o nível do reservatório e a cota limite durante as situações de quebra de restrição na simulação de operação sem previsão (linha tracejada) e com previsão com modelos (linha cinza).

\section{CONCLUSÕES}

Este trabalho avaliou os benefícios da utilização de previsões de vazão na operação de um reservatório com usos múltiplos, particularmente no caso dos conflitantes usos de geração de energia e controle de cheias.

Regras de operação simples, na forma de curvas-guia, foram utilizadas nos casos de operação com e sem previsão. As curvas-guia foram otimizadas através de uma técnica de parametrização, simulação e otimização utilizando um algoritmo evolutivo semelhante a um algoritmo genético.
Dados relativos ao reservatório de Três Marias, no rio São Francisco, foram utilizados como base para as análises. Algumas simplificações foram feitas com relação ao reservatório e a usina de Três Marias que foram utilizados como caso hipotético. Porém, como a maior parte dos resultados foi obtida em termos relativos, isto é, percentagem de benefício em relação à operação sem previsão do mesmo sistema simplificado, se acredita que as simplificações adotadas não tenham grande impacto nos resultados obtidos e que os benefícios da utilização de previsões de vazão continuem apresentando valores positivos.

Os resultados com previsão perfeita (vazões observadas) mostram que pode haver um benefício relativo de aproximadamente $8 \%$ se forem utilizadas as previsões de vazão de longo prazo com dois meses de antecedência, e se a operação for planejada com essa antecedência. Em termos absolutos isto significa que o mesmo reservatório (Três Marias) poderia gerar $8 \%$ mais energia ao longo do mesmo período de tempo, sem comprometer o controle de cheias.

A operação baseada em previsões de prazos, ou horizontes, mais curtos apresenta benefícios inferiores, mas ainda assim significativos. Por exemplo, a previsão perfeita com freqüência semanal e horizonte de 12 dias pode trazer um benefício de aproximadamente 4,45 \% (período 1964 a 2001). Em termos absolutos este benefício representa cerca de 2,75 milhões de dólares anuais, sem comprometer o funcionamento do reservatório no controle de cheias.

Esses benefícios em termos relativos são praticamente os mesmos, no caso de previsões de curto ou longo prazo, se o reservatório é operado no período 1931-1964 com base nas curvas-guia do período 1964-2001.

Outro ponto de interesse representa o fato que os benefícios da previsão, para uma mesma freqüência, aumentam na medida em que se utilizam previsões com maiores horizontes, como era esperado. Porém, neste trabalho foi demonstrado que, para o estudo de caso realizado, considerando um horizonte de 30 dias e utilizando previsões com freqüência de 30 dias (mensal), os benefícios obtidos representam apenas $50 \%$ dos benefícios que podem ser obtidos se utilizada uma freqüência diária ou semanal. Isto significa que a freqüência da previsão também é um elemento importante a ser considerado.

Embora os benefícios sejam praticamente os mesmos considerando uma freqüência diária ou semanal e um horizonte de 30 dias, na medida em que o horizonte diminui, as diferenças nos benefí- 
cios se tornam notórias. Assim, no caso de uma freqüência diária e uma semanal e um horizonte de 12 dias, a diferença nos benefícios a favor da primeira é de cerca de 0,80 milhões de dólares por ano, aproximadamente.

Os benefícios obtidos com as previsões reais de curto prazo são inferiores aos benefícios obtidos com as previsões perfeitas de curto prazo, como era esperado. Entretanto, a redução do benefício é relativamente pequena no período analisado. Utilizando previsões de vazão obtidas a partir de previsões quantitativas de chuva no período 1996-2001, foi possível obter previsões que resultaram num benefício relativo de 3,52\%, que representa cerca de 2,05 milhões de dólares anuais. Este benefício foi obtido com o mesmo desempenho no controle de cheias considerando as curvas-guia otimizadas no período de 1964 a 2001.

O valor de 3,52\% pode ser considerado alto, se for comparado ao benefício relativo que seria obtido, para o mesmo período, utilizando previsões perfeitas de vazão, que chega a 5,33\%. Em outras palavras, a previsão de vazão baseada na previsão de chuva disponível atualmente pode trazer um benefício maior do que a metade do benefício que seria esperado com a previsão perfeita de vazão para o mesmo sistema.

$\mathrm{Na}$ segunda avaliação do desempenho da operação do reservatório com base nas previsões de vazão obtidas a partir de previsões quantitativas de chuva foi demonstrado que, além de serem obtidos benefícios por uma maior geração de energia (em torno de 0,47 milhões de dólares por ano), a utilização da previsão de vazão na operação de um reservatório pode antecipar a ocorrência de cheias maiores às esperadas implicitamente pela adoção de uma curva-guia, atenuando as magnitudes das quebras de restrição e diminuindo a duração dessas quebras. Embora se possam apresentar quebras marginais da restrição no nível limite do reservatório por causa dos erros nas previsões (aconteceram três com um valor inferior a $15 \mathrm{~cm}$, em quanto que sem previsão aconteceu apenas uma, mas com um valor de quase um metro) elas podem ser minimizadas deixando uma pequena folga nas curvas-guia definidas com base na previsão perfeita de vazão afluente ao reservatório.

Os benefícios econômicos encontrados neste trabalho referem-se a apenas um reservatório, operando de forma isolada. É possível que a operação de um sistema mais complexo tenha benefícios ainda maiores a obter a partir de boas previsões de vazão quando houver sinergia de um sub-sistema e mesmo do conjunto de sub-sistemas brasileiros, considerando aí as complementaridades climáticas.

Os resultados obtidos são promissores e mostram que há vantagens evidentes na utilização de previsões quantitativas de chuva para se obter previsões de vazão na operação de reservatórios com usos múltiplos.

\section{AGRADECIMENTOS}

$\mathrm{O}$ primeiro autor agradece à Universidade Nacional do Nordeste (UNNE, Argentina) pelo financiamento de seus estudos de mestrado no qual foi feita essa pesquisa e ao CNPQ pela bolsa de doutorado concedida.

\section{REFERÊNCIAS}

ANEEL, AGÊNCIA NACIONAL DE ENERGIA ELÉTRICA. (2006). Capacidade de Geração do Brasil - In: BIG Banco de Informações de Geração. http://www. aneel.gov.br.

BRAVO, J.M.; COLLISCHONN, W.; PILAR, J.V.; SILVA, B.C.; TUCCI, C.E.M. (2005). Operação de um reservatório com múltiplos usos com base na previsão de curto prazo de vazão. Revista Brasileira de Energia, (112), p. 85-110.

BRAVO, J.M. (2006). Otimização da operação de um reservatório com base na previsão de vazão. Dissertação (Mestrado em Recursos Hídricos e Saneamento Ambiental) - IPH/UFRGS. Porto Alegre. $152 \mathrm{p}$.

BRAVO, J.M.; COLLISCHONN, W.; PILAR, J.V.; TUCCI, C.E.M. (2006). Otimização de regras de operação de reservatórios utilizando um algoritmo evolutivo. In Anais do I Simpósio de Recursos Hídricos do SulSudeste, Curitiba, PR, 1 CD.

BRAVO, J.M.; COLLISCHONN, W.; PILAR, J.V.; TUCCI, C.E.M. (in press). Otimização de regras de operação de reservatórios com incorporação da previsão de vazão. Revista Brasileira de Recursos Hídricos.

COLLISCHONN, W.; TUCCI, C. E. M. (2001). Simulação hidrológica de grandes bacias. Revista brasileira de Recursos Hídricos (6-1), p. 95-118.

COLLISCHONN, W.; TUCCI, C. E. M.; CLARKE, R. T.; DIAS, P. L. S.; OLIVEIRA, G. S. (2005a). Previsão sazonal de vazão na bacia do rio Uruguai 2: Previsão climática-hidrológica. Revista Brasileira de Recursos Hídri$\cos (10-4)$, p. 61-72. 
COLLISCHONN, W; HAAS, R.; ANDREOLLI, I.; TUCCI, C.E.M. (2005b). Forecasting River Uruguay flow using rainfall forecasts from a regional weatherprediction model. Journal of Hydrology 305, p. 87-98.

GEORGAKAKOS, A.P. (1989). The value of streamflow forecasting in reservoir operation. Water Resource Bulletin (25-4), p. 789-800.

GEORGAKAKOS, K.P.; KRZYSZTOFOWICZ, R. (2001) Probabilistic and ensemble forecasting. Journal of Hydrology 249, p.1.

GEORGAKAKOS, A.; YAO, H.; MULLUSKY, M.G.; GEORGAKAKOS, K.P. (1998). Impacts of climate variability on the operational forecast and management of the upper Des Moines River basin. Water Resources Research (34-4), p. 799-821.

HAMLET, A. F.; HUPPERT, D.; LETTENMAIER, D. P. (2002). Economic values of long-lead streamflow forecasts for Columbia River hidropower. Journal of the Water Resources Planning and Management (128-2), p. 91101.

MAURER, E. P.; LETTENMAIER, D. P. (2004). Potential effects of long-lead hydrologic predictability on Missouri River main-stem reservoirs. Journal of Climate 17, p. 174-186.

MISHALANI, N. R.; PALMER, R. N. (1988). Forecast uncertainty in water supply reservoir operation. Water Resources Bulletin (24-6), p. 1237-1245.

SILVA, B. C. (2005). Previsão hidroclimática de vazão para a bacia do rio São Francisco. Tese (Doutorado em Recursos Hídricos e Saneamento Ambiental) - IPH/UFRGS, Porto Alegre, $227 \mathrm{p}$.

TUCCI, C. E. M.; CLARKE, R. T.; COLLISCHONN, W.; SILVA, B. C.; DIAS, P. L. S.; CARDOZO, A. O.; JUAREZ, R. N.; MARENGO, J. A.; TOMASELLA, J.; SAMPAIO, G.; CHAN, C. S. (2004). Previsões de vazões na bacia do rio São Francisco com base na previsão climática. Projeto financiado por ANEEL/OMM, $367 \mathrm{p}$.

YAO, H.; GEORGAKAKOS, (2001). A. Assessment of Folsom Lake response to historical and potential future climate scenarios 2. Reservoir management. Journal of Hydrology 249, p. 176-196.

YEH, W. W-G.; BECKER, L.; ZETTLEMOYER, R. (1982). Worth of inflow forecast for reservoir operation. Journal of the Water Resources Planning and Management Division (108-WR3), p. 257-259.

\section{Assessment of Streamflow Forecast Benefits in Reservoir Operation}

\section{ABSTRACT}

This study assesses incremental benefits that might be obtained from the use of short-term and long-term streamflow forecasts in the operation of a multipurpose reservoir focusing on two water uses: flood control and power generation. The Três Marias dam, in the São Francisco river basin, was selected for study, primarily because of the availability of short-term streamflow forecast data from previous work. This streamflow forecast was estimated with a distributed hydrological model that uses a combination of observed precipitation and quantitative precipitation forecast generated by an ETA regional model as input data, and it will here be referred to as real short-term forecast. In order to quantify the benefits of forecasts, two simulation models of reservoir operation were used. The first model defines reservoir operation without using forecasts. Meanwhile, the second model considers available forecasts in the reservoir operation. The time step used in simulation was one day. Operation rules, in the form of linear rulecurves were used in reservoir operation with and without forecast. The rule-curves were optimized through a parameterization, simulation and optimization approach with an evolutionary algorithm. Results with "perfect" forecasts (considering observed flows as a forecast) show that an 8\% improvement in hydropower generation can occur if longterm forecasts are considered with a two-month horizon, and if the operation is set very early in advance. The operation based on short-term forecasts has less benefits, but they are still significant. For instance, a short-term forecast with a 12-day lead time performed weekly has an incremental hydropower generation of $4.45 \%$. Those benefits were achieved without loss of flood control performance. The benefits achieved with real short-term forecasts were lower than those with perfect short-term forecasts, as expected. However, benefits were still achieved with the real shortterm forecasts, that could be $50 \%$ higher than those expected with the perfect flow forecasts and, consequently, the reduction of increased benefit is relatively small in the period analyzed. Results are promising and show clear advantages in using quantitative precipitation forecasts to perform streamflow forecasts in multipurpose reservoir operation.

Keywords: Benefits of streamflow forecast, optimization of reservoir operation, evolutionary algorithm, quantitative precipitation forecast, AMANDA. 